On the morning of that day a complete change came over the scene. All symptoms of catalepsy vanished; the limbs were soft and flexible, and completely subject to the will of the patient, as far as consistent with his failing strength. The power of speech was restored; the poor fellow recounted his sufferings: he had heard every word uttered in his presence, and was perfectly conscious of all that had been done to him. He had felt, he said, exeruciating pain at times; he had felt the strongest inclination to express his feelings; but had been unable to utter a word or raise a finger for the purpose. The horror of this position may be imagined. In the afternoon the patient felt conscious of approaching dissolution-he knew that he should die that night. Abont midnight I was summoned to his bed; he was then in the throes of death; in a few minutes all was quiet-he was dead. Yet for some time the appearance was so similar to the previous cataleptic condition, that this fact could not be determined with certainty. However, the expression of the face was changed; no halitus appeared on the mirror, and the heart ceased to flutter: the soft and flexible limbs soon began to stiffen with the true rigidity of death.

Unfortunately no inspection of the body was allowed.

Great Russell-street, Bloomsbury.

\section{PLACENTA PRZVIA.}

By G. F. KNIPE, EsQ., M.R.C.S., SLRGEON TO THE LEIGH DISTRICT OF THE MarTley UNION.

Mns. J-C, of this parish, aged thirty-four, pregnant with her fourth child, on March 1,1851 , after a long walk, was seized with severe nterine hremorrhage, being then in the eighth month of her pregnancy. This yielded to the local use of cold, the internal administration of astringents, and the recumbent position; but recurred, from time to time, on her endeavouring to attend to her household work.

On the 23 rd of March, at eleven A M., when coming down stairs, she was attacked with flooding, accompanied by expulsive pains. At four P.M., I saw her: countenance pallid, and its expression anxious; pulse small and thready, scarcely perceptible; skin cold, clammy, and bathed in perspiration; uterine contractions, I was told, had ceased for nearly two hours; she was actually deluged with blool. I gave her fifty drops of tincture of opium, in a glass of brandy. In ten minutes, I introduced my hand, and found the os uteri slightly patent, but easily dilatable; I passed my hand under the anterior margin of the placenta, and immediately felt the head in its proper position, but high up; I grasped the legs, and brought them down into the vagina, withont $m y$ hand exciting the slightest contraction in the womb, or any resistance from the patient. I then administered half a drachm of secale, in some brandy, and cansed pressure to be made over the uterine region. In about five minutes, contraction of the uterus was excited, slight at first, but increasing in strength as the pains recurred. In half an hour the child was born; the placenta was expelled in a few minutes after; and from that time, setting apart the large mass of clotted blood which accompanied its expulsion, she lost no more than is common in the best labours. She is gradually recovering.

The only thing in the above case I should wish to draw the attention of the profession to, is, the marked benefit derived from the ergot of rye. With regard to the question at present in agitation-viz., extraction of the placenta, or turning the child-I can give no opinion, having never tried the former plan; but out of three cases of placenta prævia which have unfortnuately occurred in my practice, two I have treated as above, with snccess as to the mothers and the loss of one child. The third was unfortumately dead when $I$ arrived at her honse.

Leigh, 1951 .

\section{CASE OF POISONING BY THE DATURA STRAMONIUM.}

By II. PARKER LAURLNCE, Ese., Assistant-Surgeon Second Belooch Battalion.

Or the evening of the 10th of February, a prisoner was brought to the General Hospital, from Bukkur Fort, in the following state :- He was quite insensible to sonnd, seeming not to hear the loudest talk; rousing and shaking lim had no effect; his eyes were partially open, and the pupils more dilated than I have ever seen. The stupor was of a drunken kind; there was no disposition to sleep, but a constant restlessness and turning of the body, attended by a most peculiar fidgety manner of twisting the fingers and catching at some imaginary object. This was varied now and then by grasping the bed-clothes very tight; his body was warm, more from this exercise of the arms than any other perceptible cause; the tongue was always rolling; the pulse rather quick; and the patient often shrunk, as if suffering from a creeping sensation over his body.

Nobody knows when or how he became so; but he was: found in this state at two A.M. It was my belief that the man was under the influence of some vegetable poison. Accordingly, a dose of seventeen grains of sulphate of zinc was given, followed by warm drinks, and wet cloths ordered to be kept. to the head. The zinc having no effect, a second dose was given, a good scruple; this likewise failed. I then used the stomach-pump, but brought nothing from the stomach. After waiting a little time, I gave fifteen grains of sulphate of copper, and directed an enema to be used, and that mustard sinapisms be placed on the nape of the neck and some way down the spine.

11.-In the same state; the emetic not acted; nor have the bowels been moved; the pulse very quick and sharp. Ordered, ipecacuanha powder, one scruple; potassio-tartrate of antimony, one grain ; and an enema of sulphate of magnesia and warm water; vomited once, and brought up several seeds of the datura; the bowels unmoved. I now bled him at the arm, taking a way fully ten ounces of blood; ordered another enema of oil of turpentine, castor oil, and tepid water; head to be shaved; cold applications thereto, and the emetic as before at two p.x. Evening - Still insensible; bowels unmoved; slight sickness, and more of the datura seeds.

12.- Bowels twice freely moved during the night, when several of the datura seeds came away. To get demulcent drinks only. Evening-A ppears to be coming round, and takes a childish notice of signs, but unable to talk.

13.-Is disposed to be very happy; lauglis and talks inces. santly; bowels open. Fivening-HIas sobered down; quite sensible, and says, that the seeds of some plant had been given him by another man, at his own request, as medicine.

Hydraball, Scinde, April 5, 1851.

\section{A flíror}

OF THE PRACTICE OF

\section{MEDICINE AND SURGERY IN THE HOSPITALS OF LONDON.}

Nulla est alia pro certo noscendi via, nisi quam plurimas et morborum, et dissectionum historias, tum aliorum proprias, collectas habere et inter se comparare.-Morgagni. De Sed. et Caus. Morb., lib. 14. Procmium.

\section{ST. BARTHOLOMEW'S HOSPITAL.}

Lesion of the Kidney; Homaturia; Suppuration; Death; Autopsy.

(Under the care of Mr. Stantey.)

IDIOpatric affections of the kidney have of late been so carefully studied and elucidated, that the physician is, in general, enabled to form a pretty accurate diagnosis, when the symptoms are sufficiently distinct. Among the latter, hamaturia might be mentioned as likely to cause a little embarrassment, as it is not always easy to ascertain from which portion of the extensive mucous membrane-beginning at the meatus and ending at the kidney-the blood proceeds. When it has been discovered that the hæemorrhage does not proceed from the urethra or bladder, and that the kidney seems at fault, it has generally been found that the most frequent cause of homaturia is the laceration of vessels of the infundibula or pelvis, produced by sudden displacement of a calculous concretion.

The effect of lacerations is shown in a very instructive manner in cases where an external injury has caused such a lesion, for the careful observation of symptoms, in these instances where the laceration is almost certain, will go far to guide us in idiopathic cases. This is, however, not the only interesting point in the case which we desire to put upon record, for an admirable opportunity is afforded by the different phases of the same, to observe the effects of certain substances used to control hæmorrhage, and likewise to follow 